\title{
ถ⿻上ิ์ \\ INTERNACIONAL \\ DE DESIGN \\ A Teoria de Solução de Problemas Inventivos (TRIZ) como complementar aos processos intuitivos de criatividade no design
}

\author{
Sérgio Luciano da Silva; \\ Felipe Domingues; \\ Maria Regina Álvares Correia Dias
}

\section{resumo:}

A partir de breve exposição histórica e descrição dos conceitos do método não intuitivo de suporte à criatividade e à criação Teoria de Solução de Problemas Inventivos (TRIZ), elaborado por Genrich Altshuller a partir de 1946, o artigo defende a ideia de que alguns dos recursos e potencialidades desse instrumento de suporte à criação podem ser complementares aos processos intuitivos no âmbito do design. $\mathrm{O}$ objetivo é investigar as capacidades deste instrumento de suporte à criação e suas potencialidades para uso no campo do design.

pallavras-chave:

TRIZ; criatividade; design; razão; intuição. 


\section{Pressupostos, hipótese, tema e objetivos}

Antes de apresentarmos a hipótese que guia o presente artigo, cabe estabelecer parâmetros para alguns termos que, devido à amplitude de seus sentidos, podem criar dificuldades para o entendimento específico de nossa proposta. Os conceitos que comumente chamamos de razão e intuição têm os mais diversos significados para estudiosos e pesquisadores, dependendo do contexto e da área de pesquisa em questão. $\mathrm{O}$ acúmulo de definições e posicionamentos em torno desses termos, ao longo de mais de 2000 anos do pensamento ocidental, torna seu uso, no mínimo problemático, caso não se estabeleça antes algum referencial de interpretação. Para evitar equívocos hermenêuticos associados a períodos históricos ou autores específicos, nos apoiamos em Ferrater Mora (1979) para estabelecer a acepção desses dois termos com que iremos trabalhar. Deste modo, consideramos aqui, intuição em seu sentido mais geral como forma de conhecimento direto, claro e imediato, que independe (pelo menos de maneira consciente) de raciocínio ou de análise (MORA, 1979, p. 1751). Da mesma maneira, fazendo par e polarizando com a intuição, razão será entendida aqui como o conhecimento estabelecido por meio de raciocínio, que conduz à indução ou dedução de algo (MORA, 1979, p. 2774). Nossa intenção é estabelecer um recorte heurístico nas múltiplas e complexas conceituações que esses termos geraram ao longo da história do pensamento ocidental. Tal escolha, de caráter mais geral nas acepções dos dois termos, se justifica, uma vez que os autores selecionados para a apresentação da teoria e do método TRIZ, até onde pudemos verificar, não avançam, como mostraremos, em posições epistemológicas restritivas.

Quando o tema em análise é design, um dos pressupostos tácitos é o de que criação e criatividade são constituintes básicos deste campo de pesquisa e de trabalho. Tanto na elaboração de conceitos quanto na geração de produtos é sempre esperado dos profissionais, isolados ou em grupos, que sejam criativos. Este caráter de necessidade da criatividade, imposto ao design e outros campos, a partir da década de 1940, tem atraído cada vez mais pesquisadores interessados na compreensão de tal fenômeno. Nesse contexto é relevante compreender melhor como o ser humano atua na solução de problemas complexos e quais os recursos e instrumentos podem ser incorporados às suas habilidades, para tornar esse processo mais eficiente, bem-sucedido e, se possível, segundo nossa posição, controlado. Parte das pesquisas, que envolvem a intuição, se volta para a descrição e prescrição de mecanismos psicológicos que podem desde auxiliar e reforçar, até disparar e catalisar processos criativos. Conforme afirmam Luciane Tudda e Adriana Santos:

Somente a partir da década de 40 , com o desenvolvimento do conhecimento referente à psicologia é que se observa maior numero de pesquisas relacionadas à criatividade. A partir da década de 1950, encontram-se teorias que propõem a explicação da criatividade com ênfase nos diferentes aspectos a ela relacionados: o pensamento criativo e os processos mentais envolvidos; a análise das fases envolvidas no processo criativo; a análise de características individuais de personalidade, traços intelectuais e cognitivos, presentes em indivíduos considerados criativos ou bloqueios individuais presentes; a análise de fatores ambientais e culturais, como facilitadores ou inibidores da manifestação da criatividade. (TUDDA; SANTOS, 2011, p. 118)

Contrastando com os estudos mais voltados aos aspectos não mediados da criatividade, há cerca de sessenta anos (1946) teve início uma investigação que busca respostas fora do âmbito da intuição e que recebeu o nome de TRIZ (sigla em russo para Teoria de Solução de Problemas Inventivos), ou método TRIZ. Os desdobramentos desses estudos e o conjunto de princípios que se instituiu a partir dessas pesquisas e vem sendo aplicado a diversos campos de desenvolvimento de produtos é o objeto do presente artigo. O principal método aplicado aqui é analítico, descritivo e comparativo, visando compreender os fundamentos do TRIZ e suas capacidades. O recorte deste estudo, ao usar a análise descritiva comparativa correlacionando características racionais e intuitivas, se restringe a apontar as diferenças estruturais e capacidade das mesmas. Maldonado, Monterrubio e Arzate (2005) discorrem sobre métodos que esses autores consideram "convencionais", como o Iterativo, Pensamento lateral, Heurístico, Brainstorm e da Cinética em contraposição ao TRIZ. No entanto, nossa posição não pretende confrontar tais métodos. Pelo contrário, como veremos, nossa hipótese é de que podemos somar esforços unindo os processos mediados aos intuitivos em prol da ampliação dos recursos criativos à disposição do design. 


\section{História e fundamentos teóricos do TRIZ}

Genrich Altshuller (1926-1998), seguido posteriormente por outros pesquisadores, elaborou o método TRIZ, a partir 1946. Para Altshuller (2007), o postulado básico do TRIZ é que os sistemas técnicos evoluem de acordo com determinadas leis. Uma vez identificadas, tais leis são identificadas elas podem ser usadas para criar algoritmos $^{l}$ capazes de solucionar problemas inventivos.

Um componente histórico importante relativo ao trabalho de Genrich Altshuller é que este pesquisador, inventor e escritor de ficção científica, era examinador de patentes da marinha russa. Isso justifica a sua defesa de que o lugar para se procurar os fundamentos de invenções e novas ideias não é o cérebro dos inventores, mas o escritório de patentes (onde invenções são reunidas, catalogadas sistematicamente e reconhecidas). A perspectiva de Altshuller, voltada para os sistemas técnicos, num certo sentido, distancia-se da romantização em torno da ideia de criação que ainda hoje permeia campos como o das belas-artes e regiões fronteiriças com o design como as da arquitetura. Olhando em retrospecto, podemos encontrar uma das raízes dessa atração pelo espírito romântico no Ocidente na formação histórica de nossa cultura.

Na história do Ocidente, sofremos a influência de diversas concepções de criação do mundo. No entanto, duas cosmogonias se destacam em nossa cultura. Uma de origem grega, em que um ser divino, um demiurgo, não cria propriamente, mas produz o cosmos ordenado a partir de uma massa informe original, o caos. Outra concepção é estabelecida pela tradição judaico-cristã, em que Deus cria tudo a partir do nada (ex nihilo). Essa segunda concepção é, em certa medida, acolhida pelo movimento romântico, em fins do século XVIII. Esse movimento cultural europeu, complexo e variado, tem como uma de suas matrizes a valorização da imaginação e da originalidade subjetiva em relação à razão, reforçando a ideia de gênio criativo inspirado. Nesse contexto, em que não é possível explicar racionalmente a criação, acaba-se por admitir que a intuição e o dom, ou talento individual, são as principais molas propulsoras de novas criações. Ora, a concepção de Altshuller afasta-se dessa visão, mitiga o valor do gênio e estabelece em seu lugar princípios, considerados por ele racionais.

\subsection{Princípios universais de criatividade}

No entanto, analisando retrospectivamente, Altshuller precisava, no momento em que desenvolvia a base da teoria para o TRIZ, além de abrir mão do conceito de criatividade intuitiva, inserir outro em seu lugar, se quisesse fundamentar minimamente suas ideias. Vejamos a interpretação de Silverstein, Decarlo e Slocum acerca da concepção de inovação em Altshuller:

Altshuller provou que os padrões definitivos de inovação podem ser aproveitados para ampliar qualquer mundo limitado em uma das possibilidades de expansão. Nesse mundo, o talento para a inovação não é um dom inato, mas uma habilidade que se pode aprender. (SILVERSTEIN; DECARLO; SLOCUM, 2008, p. 41)

Essa afirmação, se levada adiante com tal compreensão do que seja inovação, reforça a posição anterior que põe entre parênteses a visão de criatividade atrelada ao conceito de criação ex nihilo. E novamente (como no caso de buscar as soluções não no cérebro), Altshuller, no nosso entendimento, atua de forma minimalista, tornando seus conceitos enxutos. Esse minimalismo, de característica matemática, procura fornecer agilidade à sua teoria, uma vez que a mesma perde em desempenho para os processos intuitivos, por ser internamente mediada através de leis e algoritmos. A sua hipótese de investigação parte da concepção de que existem princípios universais de criatividade que são a base para a criação de inovações, que fazem avançar o conhecimento e a tecnologia.

E o que Atshuller faz a seguir? Não fica somente na teoria: procura comprovar na prática esses princípios. Assim, quando analisadas milhares de invenções, Altshuller identifica um número limitado de princípios para as mesmas (MALDONADO; MONTERRUBIO; ARZATE, 2005, p. 35). Posteriormente, codifica oito padrões evolucionários para guiar decisões estratégicas, estabelece 40 princípios, 76 padrões de soluções e 39 parâmetros para caracterização de problemas (SILVERSTEIN; DECARLO; SLOCUM, 2008, p. 41). Uma vez que estes princípios puderam ser identificados e

\footnotetext{
${ }^{1}$ Algoritmo entendido como uma sequência de raciocínios que contém um conjunto de regras e dados finitos sendo utilizado para solucionar problemas de classes semelhantes.
} 
codificados, o método TRIZ foi estabelecido e divulgado aos profissionais de diversos campos com a promessa de tornar o processo de criatividade mais previsível.

$\mathrm{Na}$ verdade, a estratégia e o caminho percorrido por Altshuller não são novos. Se passarmos em revista a história das idéias, veremos que a abordagem de Altshuller é recorrente. A ideia de elaborar princípios e padrões a partir do que já está estabelecido como solução de problemas é antiga e um dos pilares para o conhecimento cumulativo. Com tantos registros armazenados acerca de invenções, em algum lugar alguém já pode ter resolvido o problema que se enfrenta ou um muito semelhante a ele. Como afirmam Silverstein, Decarlo e Slocum:

Embora, tecnicamente cada patente seja única, em nível genérico há realmente apenas um número muito limitado de problemas e soluções em todo o mundo através de todos os tempos! Por mais difícil que isso possa parecer, é verdade. Os milhões de inovações feitas através do tempo são realmente apenas uma função de um conjunto muito pequeno de parâmetros, princípios e padrões. (SILVERSTEIN; DECARLO; SLOCUM, 2008, p. 39)

De qualquer modo, mesmo se não concordamos com o caráter geral desses argumentos, que podem ser interpretados como reducionistas, uma reflexão sobre um aspecto diverso dessa questão pode nos ampliar a compreensão sobre os fundamentos do TRIZ. A proposta de Altshuller leva em conta certo distanciamento do observador em relação ao seu objeto de estudo. Se pensarmos na maneira como nós mesmos atuamos, não é difícil entender que cada pesquisador está tão envolvido com seu campo de estudo que reduz sua atenção na observação de áreas correlatas. Neste sentido, é relevante o fato de Altshuller basear-se nas suas vivências em um escritório de patentes na Rússia. Isso fez dele um observador privilegiado, como já ocorrera também com Albert Einstein ao trabalhar em um escritório de patentes na Suíça. É interessante notar que Einstein também considerava estimulante, para as suas atividades científicas, o período em que trabalhou com patentes. Conforme as próprias palavras de Einstein:

Trabalhar na formulação final de patentes tecnológicas era uma verdadeira bênção para mim. Obrigou-me a um pensamento multifacetado e também forneceu estímulos importantes para o pensamento físico. (FOLSING, 1997, p. 102)

Assim, com relação ao distanciamento, tanto Einstein quanto Altshuller podem ser vistos como outsiders, já que partes de suas teorias foram desenvolvidas no período de trabalho nesses escritórios de patente, ou seja, não enquanto atuavam como pesquisadores dentro da academia. E esse componente de distanciamento, pelo menos na concepção de Altshuller, foi levado em conta na constituição de sua teoria.

Por outro lado, não devemos considerar que o fato de não ser um acadêmico possa retirar parte da força reflexiva dos argumentos de Altshuller. Esse risco existe se nos ativermos apenas aos seus procedimentos enquanto esse pesquisador compilava dados no escritório de patentes. No entanto, a existência de um construto teórico afasta a possibilidade de interpretarmos as análises como um compêndio ou um mero catálogo de soluções inventivas que, por serem finitas, oferecem possibilidades finitas. E o que caracteriza sua busca por fundamentação (independentemente dos resultados posteriores que são obtidos com a aplicação do TRIZ) é a compreensão de que as invenções bem-sucedidas são entendidas como gatilhos de processos similares em diversas áreas e por isso podem se extrair delas princípios, padrões e parâmetros. Nesse ponto, sua concepção, mesmo que ele não explicite isso, vai ao encontro a conceitos universais, ou seja, tem características de uma teoria consistente e com viés platônico.

Mas o que realmente caracteriza o TRIZ? Por um lado, os processos intuitivos, como o Brainstorming (DIAS, 2007), buscam solução não mediada, mas com resultados imprevisíveis e não repetíveis. Por outro, o que o TRIZ propõe é a capacidade de resolução de problemas baseada em lógica e dados, com uma estrutura algorítmica. Assim, com um roteiro em mãos, é possível, segundo a teoria, se chegar à solução de problemas de maneira mediada, mas fornecendo 
repetição, previsibilidade, confiabilidade e aceleração da capacidade das equipes envolvidas na busca de solução para problemas de forma criativa ${ }^{2}$.

Atentos a essas características, poderíamos pensar que o TRIZ, ao ser posicionado com uma abordagem algorítmica, contrapõe e contesta os processos intuitivos. No entanto, como veremos adiante, os processos intuitivos e racionais não se excluem, e, no nosso entendimento, podem e devem ser entendidos como complementares.

\subsection{Ataque às contradições}

Além das características vistas anteriormente, o TRIZ tem como um de seus fundamentos um preceito que é imposto àqueles que pretendem seguir esse método. Na verdade, este fundamento é antes de tudo uma atitude diante das contradições que aparecem durante o processo de criação. Ao contrário de evitá-las, uma equipe que procura resolver um problema deve sempre ir em sua direção, na busca por eliminá-las. Uma vez que esse enfrentamento intenta conduzir equipes de criação, devidamente preparadas, até as soluções, o TRIZ deve oferecer às mesmas entendimento do que sejam as contradições. E o significado de contradição se dá dentro de uma relação em que ocorre incompatibilidade entre dois termos, isto é, quando se afirma um termo, ao mesmo tempo, nega-se outro e vice-versa. O método TRIZ normatiza as contradições em duas categorias: técnicas e físicas (MALDONADO; MONTERRUBIO; ARZATE, 2005, p. 66-69).

Nas contradições técnicas, quando algo funciona, algo se atrapalha. Por exemplo, uma lata de alumínio para refrigerante deve ter as paredes finas para economizar metal e ser mais barata (atributo desejável), mas ao mesmo tempo pode se romper pela pressão interna (atributo indesejável). Como economizar metal e manter o recipiente resistente?

Nas contradições físicas algo tem necessidades opostas. Por exemplo, uma fábrica precisa produzir vidros com $1 \mathrm{~mm}$ de espessura. Mas ao mesmo tempo esses vidros, tão finos, precisam ter cantos arredondados. Como arredondar os cantos sem quebrar os vidros?

Vale ressaltar que não é a intenção deste estudo elencar soluções, mas um exemplo de contradição, que se resolve em solução, é o da corrente de bicicleta. Concebida e estruturada com anéis de metal, seu mecanismo é ao mesmo tempo rígido no nível micro e flexível no macro. Assim, sua estrutura, concepção e solução para um determinado problema, podem e devem, segundo o método TRIZ, ser apropriadas e aproveitadas em outros campos que eventualmente apresentem problemas e necessidades semelhantes.

\subsection{Mediação e paciência}

Lamentavelmente, o TRIZ, enquanto processo de pensamento metódico e mediado, pode ser uma barreira à sua utilização e aplicação, uma vez que em uma tarefa de criação ou solução de problemas, o tempo inicial consumido na análise das contradições e limitações costuma afastar equipes interessadas em rápidos resultados. Deste modo, além das contradições, um segundo preceito deve ser levado em conta. Tal recomendação diz respeito à paciência que o indivíduo ou a equipe de criação devem ter na busca por soluções para um determinado problema. Há que se ter calma e disposição para enfrentar o problema buscando solução no interior das contradições. Como afirmam Silverstein, Decarlo e Slocum:

Isto é o que Altshuller proporcionou: o uso de algoritmos simples para resolver problemas intratáveis, resolver as contradições técnicas mais difíceis, e possibilitar produtos e serviços inovadores. Em vez de procurar respostas em lugares convenientes, TRIZ torna conveniente encontrar respostas em lugares difíceis. (SILVERSTEIN; DECARLO; SLOCUM, 2008, p. 42)

\footnotetext{
${ }^{2}$ Lembremos que, neste caso, ser criativo é encontrar uma solução já existente para um problema já resolvido e aplicá-la ao que se está trabalhando atualmente.
} 
A busca de respostas em "lugares difíceis" está associada à idéia de mediação. Se a equipe de criação procura ir o mais rapidamente possível para a solução, pode não despender tempo suficiente na definição do problema. A mediação permite filtrar e aprofundar as perguntas levando até a contradição fundamental, que precisa ser tratada, para atingir o resultado ideal que se procura. Além disso, um olhar metódico em um sistema e seus arredores (para os recursos que podem ser usados para resolver o problema) também exige paciência e minúcia.

\section{Expansão e resultados}

Do ponto de vista pragmático, o TRIZ vem se expandindo ao longo dos anos e são vários os usos corporativos através de caminhos paralelos como, por exemplo, gerenciamento de processos produtivos ou administrativos, gestão de projetos, sistemas de gestão de risco e iniciativas de inovação organizacional. Maldonado, Monterrubio e Arzate (2005, p.36-37) apresentam uma lista de empresas que se destacam no mercado global e que vem se beneficiando com o método em ações específicas:

- $\quad \mathrm{BOSCH}$ - Gerar inovações em seus componentes automotores.

- BMW - Reduzir o número de parte de seus motores ao mesmo tempo em que se incrementa a sua potência.

- DELPHI - Desenvolver freios de última geração.

- FERRARI - Aperfeiçoar componentes chave de seus motores.

- INTEL - Agilizar o desenvolvimento de novos sistemas de produção.

- NESTLÉ - Acelerar a produção de chocolate com redução de custos.

- PROCTER \& GAMBLE - Otimizar processos e produtos (incremento de até $200 \%$ no número de patentes geradas).

- SHELL - Aperfeiçoar a prospecção e refinamento de petróleo.

- TOYOTA - Reduzir partes de seus motores.

Esses mesmos autores afirmam que os resultados preliminares das várias fases da pesquisa indicam que problemas e soluções são repetidos nas indústrias e nas ciências. A classificação das contradições, em cada problema, prediz soluções criativas para aquele problema, padrões de evolução técnica repetem-se tanto em indústrias quanto no âmbito científico e inovações criativas podem usar efeitos científicos fora do campo onde foram desenvolvidas. Ora, o posicionamento de Maldonado, Monterrubio e Arzate (2005) se alinha com a proposta deste artigo de avaliar as potencialidades do TRIZ no campo específico do design. Mas apostar nessa possibilidade exige que submetamos antes a teoria que fundamenta o método ao crivo de uma crítica aos seus pressupostos e conceitos.

\section{Crítica e proposta de atuação complementar}

Como qualquer constructo que une conceitos teóricos e práticos, como os que caracterizam o TRIZ, uma série de críticas podem ser interpostas. Com o intuito de testarmos as capacidades desse método e de explicitar tanto os ataques aos pontos que acreditamos mais vulneráveis de nosso objeto de estudo bem como os possíveis argumentos que podem ser estabelecidos em sua defesa, elaboramos e separamos três categorias de críticas. É preciso deixar claro que, até onde pesquisamos, não encontramos críticas dessa ordem estabelecidas pelas comunidades científica e técnica. As críticas que apresentamos a seguir, hipoteticamente, são como testes de falseabilidade como propostos por Karl Popper (1994) na busca de lacunas e limitações em teorias de caráter científico. Se o TRIZ suportar, ao menos em parte, as críticas, talvez possamos avançar em nossa proposta de inseri-lo como instrumento balizado na atuação complementar aos processos intuitivos de criação no campo do design. 


\subsection{Crítica epistemológica}

Em nosso entendimento, um ponto central para se estabelecer parâmetros para uma crítica arrazoada a um determinado método ou técnica processual, diz respeito às posições epistêmicas, que seus autores, explícita ou implicitamente, defendem quanto à constituição da sua teoria. No caso do TRIZ, acreditamos que exista uma composição entre teoria e experiência que tornam a organização interna de seus processos robusta o bastante para vencer, pelo menos, dualismos epistemológicos. Isso é possível porque, por um lado, a visão conceitual racionalista de Altshuller e de seus seguidores lembra o esforço e a intenção de filósofos e matemáticos como Platão e Descartes, buscando entendimento e controle do mundo através de um modelo calcado em um modo de operar matemático (mathesis universalis), que vai do particular ao universal. Por outro, o método criado, a partir dessa teoria racionalista, funda seus princípios em estreita comunhão ao conteúdo e resultado já estabelecido de experiências bem-sucedidas na prática anterior e que tem contornos empiristas. Ora, se essa junção de racionalismo e empirismo pode parecer a princípio paradoxal, devemos nos lembrar que Kant, já ao final do século XVIII, propõe um modelo com essas características e com reais vantagens sobre seus predecessores isolados. Além disso, se as experiências se originam na criação mental, observação da natureza, ou por meio de outro tipo de ação do pesquisador / inventor / descobridor, essa etapa, acreditamos, não importa para o processo interno proposto pelo TRIZ. Neste sentido, a posição de Altshuller não pode ser considerada nem racionalista nem empirista, stricto sensu, o que limita o alcance de críticas dessa ordem.

\subsection{Crítica cognitiva}

Com relação à querela que pode se estabelecer acerca da primazia da razão sobre a intuição ou viceversa, até onde pudemos ver, não encontramos nada sobre os princípios do TRIZ que invalide os processos ligados à intuição. Os autores consultados defendem o TRIZ como qualquer autor defende sua criação. Além disso, não nos parece que Altshuller questione as conquistas que foram estabelecidas por meio de processos intuitivos, mas sim as limitações da intuição enquanto operação cognitiva. No nosso entendimento, esse é ponto que põe por terra a crítica cognitiva.

De nossa parte, acreditamos que não somente intuição e razão se complementam. As falhas inerentes aos projetos epistemológicos, racionalista e empirista, que alcançaram seus extremos e limitações na época moderna, deveriam servir-nos de alerta quanto às reais capacidades das concepções pautadas em um purismo conceitual excludente.

\subsection{Crítica ontológica}

Esta terceira e última crítica, acreditamos, seja a mais aprofundada e de difícil defesa. Ela vai de encontro não propriamente ao arcabouço conceitual do TRIZ, mas questiona o alcance e a capacidade de atuar que esse método pode ter em relação a algumas classes de objetos. A crítica, portanto, não recai sobre os princípios e fundamentos do TRIZ, mas especificamente sobre a proposta deste artigo de ampliar o campo de ação desse método para além do que defendem seus autores.

Suponhamos que algum crítico afirme que, na prática, os exemplos de soluções dados pelo TRIZ estão circunscritos a áreas especificas do desenvolvimento de produtos. Tal crítico, apoiando-se tanto no direcionamento do TRIZ para os chamados sistemas técnicos, quanto nos próprios exemplos fornecidos anteriormente, argumentará que empresas como Bosch, BMW, Ferrari e Delphi estão voltadas para inovações em sistemas mecânicos e eletrônicos de uso específico em áreas de engenharia e com soluções não voltadas para interações e interfaces com o usuário.

Mais ainda, tendo em vista que esses produtos não têm relação direta com seus usuários, pertencem a uma categoria de objetos que não estabelecem vínculos diretos com quem os utiliza e, consequentemente, têm as prioridades de seu desenvolvimento, por parte das empresas que os fabricam, voltadas principalmente para razões funcionais e instrumentais. Para reforçar conceitualmente seus argumentos tal crítico se apropria da clássica divisão de Jean Baudrillard, estabelecida ao final da década de 1960, acerca de objetos de uso cotidiano e de objetos técnicos. Nesta bipartição os objetos de uso cotidiano exigem de quem os estuda a compreensão de diversos 
elementos, conceitos e aspectos que os objetos técnicos não cobram. Baudrillard, atento ao que ele nomeia de "tecnologia estrutural", afirma que esta área.

[...] só pode se exercer rigorosamente em setores restritos que vão das pesquisas de laboratório às realizações altamente técnicas tais como a aeronáutica, a astronáutica, a marinha, os grandes caminhões de transporte, as máquinas aperfeiçoadas, etc., em pontos onde a urgência técnica faz atuar a fundo a coerção estrutural, onde o caráter coletivo e impessoal reduz ao mínimo o domínio da moda. Enquanto o automóvel se consome no jogo das formas mantendo um estatuto tecnológico minoritário (refrigeração por água, motor de cilindros, etc.) a aviação é obrigada a produzir os mais concretos objetos técnicos por simples razões funcionais (segurança, rapidez, eficácia). Nesse caso, a evolução tecnológica segue uma linha quase pura. Mas é claro que, para dar conta do sistema cotidiano dos objetos, esta análise tecnológica estrutural é insuficiente. (BAUDRILLARD, 2004, p. 13)

Avançando um pouco mais, Baudrillard exemplifica como forma de cercar melhor sua distinção:

Tomemos um exemplo: aquilo que é "essencial" e estrutural, portanto o mais concretamente objetivo em um moedor de café, é o motor elétrico, é a energia distribuída pela central, são as leis de produção e de transformação da energia - o que é já menos objetivo uma vez que ligado à necessidade desta ou daquela pessoa, é a sua função precisa de moer o café - o que já não é de modo algum objetivo, portanto, inessencial, que ele seja verde ou retangular, rosa ou trapezoidal. Uma mesma estrutura, o motor elétrico, pode especificar-se em diversas funções: a diferenciação funcional é já segunda (de onde pode cair na incoerência do gadget). O mesmo objetofunção por sua vez pode especificar-se em diversas formas: estamos aqui no domínio da "personalização", da conotação formal, que é o do inessencial. (BAUDRILLARD, 2004, p. 14-15)

Se aceitarmos essa terceira crítica e concordarmos com a divisão estabelecida por Baudrillard, nossa posição somente se sustenta como uma aposta nas capacidades do TRIZ de ir além dos sistemas técnicos e seus objetos em direção ao "inessencial". Se a complexidade das relações a que estão sujeitos os objetos de uso cotidiano podem exigir soluções que estariam fora das capacidades do TRIZ, talvez só possamos saber, a partir do momento em que o mesmo for aplicado em soluções dessa natureza.

\subsection{O uso complementar do TRIZ}

Assim, apostando na possibilidade anterior, é principalmente a partir das práticas atuais de profissionais de criação que acreditamos ser possível pensar uma defesa para o uso complementar do TRIZ em conjunção com elementos e processos intuitivos. Nossa proposta é de que, para aqueles que não se interessam por explorar a intuição e buscam administrar cada etapa do processo criativo, o TRIZ, até onde pudemos ver, parece oferecer um roteiro controlável. Mesmo nestes casos, talvez mais ao gosto de profissionais ligados às engenharias e ciências exatas, é possível pensar em uma rotina de trabalho que privilegie a razão e o algoritmo, o que não exclui uma solução intuitiva, se a mesma ocorrer, espontaneamente, como geralmente ocorre, durante o trajeto racional. Quanto àqueles que privilegiam a intuição (entre os quais se encontram profissionais do design e demais envolvidos com linguagens figurativas e imagéticas) e que justificam que em seus campos de trabalho os poderes da intuição ultrapassam em muito o instrumental matemático, devemos observar que seus procedimentos intuitivos já incorporam alguns preceitos defendidos pelo TRIZ. São exemplos disso, como vimos, a paciência e a atenção aos campos correlatos que reforçam a atuação intuitiva, bem como a busca por referências externas ao problema e que vão se acumulando e saturando a mente até que ocorra o insight. 
Por fim, acreditamos que se conseguirmos defender a ideia de que ser criativo também pode ser encontrar uma solução existente para um problema já resolvido, adaptá-la e aplicá-la ao que se está trabalhando atualmente, poderemos ampliar a difusão do TRIZ no âmbito do design.

\section{Considerações Finais}

Restam questões com relação ao método TRIZ, nascidas ao longo de nossa pesquisa e da elaboração deste artigo, que ainda encontram-se sem respostas e estimulam reflexões futuras.

Primeiro, quando pensamos que, por exemplo, uma teoria como a da mecânica quântica, responsável por um terço do PIB dos Estados Unidos ${ }^{3}$, se fundamenta em conceitos contraditórios, que não são resolvidos, mas aceitos como aspectos complementares de uma mesma concepção formal e matemática, podemos nos perguntar: será que, enquanto profissionais, ao fazermos uso do método TRIZ, temos sempre que enfrentar e resolver contradições?

Segundo, se o TRIZ tem um número limitado de princípios, padrões, contradições e algoritmos, suas soluções podem engessar o processo criativo em um número finito de soluções ou esse método seria, fazendo o uso de uma metáfora, como o alfabeto latino (e outras escritas) que com apenas 26 letras permite a construção virtual de qualquer palavra?

\section{The Theory of Inventive Problem Solving (TRIZ) as a complement to the intuitive processes of creativity in design}

Abstract: The article copes with the idea that some of the resources and potentialities of the Theory of Inventive Problem Solving (TRIZ), posited by Genrich Altshuler (1946), can support intuitive design processes. Building on a brief historical account and a description of the TRIZ concepts as a nonintuitive method to support creativity and creation, the article aims to investigate the capabilities of this instrument to support creation and its potentialities for use in the field of design.

Keywords: TRIZ; creativity; design; reason; intuition.

\section{Referências bibliográficas}

ALTSHULLER, Genrich. The innovation Algorithm. Translated and edited by Lev Shulyak and Steven Rodman. Worcester: Technical Innovation Center, Inc. $2^{\text {nd }}$ Ed.: 2007.

BAUDRILLARD, Jean. 0 sistema dos objetos. Trad. Zulmira Ribeiro Tavares. São Paulo: Perspectiva, 2004.

CHAVES, Alaor; SHELLARD Ronald Cintra. Física para o Brasil, pensando o futuro: o desenvolvimento da física e sua inserção na vida social e econômica do país. São Paulo: Sociedade Brasileira de Física, 2005.

DIAS, Maria Regina A. C. A criatividade na solução de problemas. In: $4^{\circ}$ Congresso Internacional de Pesquisa em Design - Brasil 2007, Rio de Janeiro. Anais do $4^{\circ}$ Congresso Internacional de Pesquisa em Design. Rio de Janeiro, 2007.

\footnotetext{
${ }^{3}$ Estimativa relacionada ao PIB dos Estados Unidos para o ano de 2001, segundo Leon Lederman, físico norteamericano ganhador do Prêmio Nobel de Física de 1988. Lederman tem em conta as tecnologias elaboradas a partir da teoria da física quântica, e que deram origem, por exemplo, ao transistor e seus derivados, ao raio laser e à fibra óptica. (CHAVES; SHELLARD, 2005, p. 15)
} 
FOLSING, Albrecht. Albert Einstein: a biography. Translated from the German by Ewald Osers. New York: Viking, 1997.

MALDONADO, Margarito C.; MONTERRUBIO, Rafael O.; ARZATE, Enrique R. TRIZ, la metodologia mas moderna para inventar o inovar tecnologicamente de manera sistemática. México: Panorama Editorial, 2005.

MORA, J. F. Diccionario de filosofia. Madrid: Alianza Editorial, 1979.

POPPER, Karl R. Conjecturas e refutações. Brasília: Ed. UnB, 1994.

SILVERSTEIN David; DECARLO Neil; SLOCUM Michael. Insourcing innovation: how to achieve competitive excellence using TRIZ. New York: Auerbach Publications/Taylor \& Francis Group, 2008.

SAVRANSKY, Semyon D. Engineering of creativity: introduction to TRIZ methodology of inventive problem solving. New York: CRC Press, 2000.

TUDDA, Luciane ; Baraldi, Adriana Alves dos Santos. Teorias para o Desenvolvimento da Criatividade Individual e Organizacional. Revista Administração em Diálogo - RAD, v. 13, p. 116-133, 2011. 